\title{
Modelling of Dynamical Properties of a Resonant Converter under Step Frequence- and Loaded Converter Changes
}

\author{
Michal Prazenica \\ Faculty of Electrical Engineering \\ University of Zilina \\ Zilina, Slovak Republic \\ Juraj Koscelnik \\ Faculty of Electrical Engineering \\ University of Zilina \\ Zilina, Slovak Republic
}

\author{
Slavomir Kascak \\ Faculty of Electrical Engineering \\ University of Zilina \\ Zilina, Slovak Republic
}

\section{Ivan Lovas}

Freescale Semiconductor Inc.

Roznov pod Radhostem, Czech Republic

$$
\begin{aligned}
\frac{\mathrm{d} i_{L 2}}{\mathrm{~d} t} & =\frac{1}{L_{1}} u_{C 2} \\
\frac{\mathrm{d} u_{C 1}}{\mathrm{~d} t} & =\frac{1}{C_{1}} i_{L 1} \\
\frac{\mathrm{d} u_{C 2}}{\mathrm{~d} t} & =\frac{1}{C_{2}} i_{L 1}-\frac{1}{C_{2}} i_{L 2}-\frac{1}{r_{2} C_{2}} u_{C 2}-\frac{1}{C_{2}} i_{L L} \\
\frac{\mathrm{d} i_{L L}}{\mathrm{~d} t} & =\frac{1}{L_{L}} u_{C 2}-\frac{R_{L}}{L_{L}} i_{L L}
\end{aligned}
$$

where

Keywords-dynamical state-space model; modelling and simulation; resonant converter; LCTLC inverter; voltage transfer characteri-stic; steady-state operation; transient phenomena.

\section{INTRODUCTION - RESONANT CONVERTER MATHEMATICAL MODEL}

One of the novel types of converters is LCTLC inverter [1] (Figure 1.), loaded either by simple RL load or bridge connected rectifier.

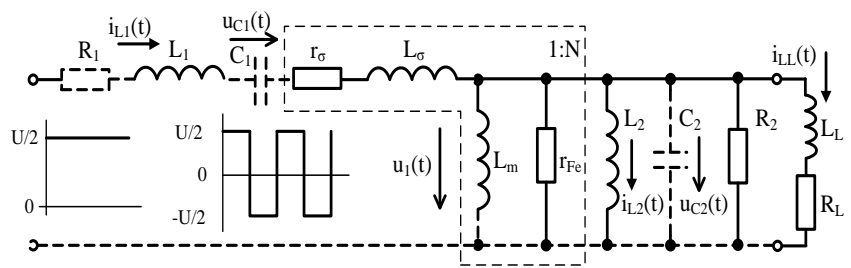

\section{FIGURE I. EQUIVALENT CIRCUIT OF LCTLC INVERTER WITH RL

$$
\text { LOAD }
$$

The dynamical model of resonant inverter can be created by using of different approaches [2], [3]. State-space operation of the LCLC filter is investigated in [4], [5].The state-space equations for equivalent circuit with R-L load yield

$$
\frac{\mathrm{d} i_{L 1}}{\mathrm{~d} t}=-\frac{r_{1}}{L_{1}} i_{L 1}-\frac{1}{L_{1}} u_{C 1}-\frac{1}{L_{1}} u_{C 2}+\frac{1}{L_{1}} u_{1}
$$

$i_{L 1}, i_{L 2}$ - currents through the inductors $L_{1}$ and $L_{2}$, respectively

$i_{L L}$ - current through the load $R_{\text {load }}, L_{\text {load }}$

$u_{C 1}, u_{C 2}$ - capacitors voltages of $C_{1}$ and $C_{2}$, respectively

$u_{1}(t)$ - output voltage of the converter (filter's input voltage).

Thus, we can rewrite system equation (1) into matrix form (2)

$$
\begin{aligned}
& \frac{\mathrm{d}}{\mathrm{d} t}\left(\begin{array}{c}
i_{L 1} \\
i_{L 2} \\
u_{C 1} \\
u_{C 2} \\
i_{L L}
\end{array}\right)=\left(\begin{array}{ccccc}
-r_{1} / L_{1} & -1 / L_{1} & -1 / L_{1} & 0 & 0 \\
0 & 0 & 0 & 1 / L_{1} & 0 \\
1 / C_{1} & 0 & 0 & 0 & 0 \\
1 / C_{2} & -1 / C_{2} & 0 & -1 / r_{2} C_{2} & -1 / C_{2} \\
0 & 0 & 0 & 1 / L_{L} & -R_{L} / L_{L}
\end{array}\right) \\
& \mathrm{x}\left(\begin{array}{c}
i_{L 1} \\
i_{L 2} \\
u_{C 1} \\
u_{C 2} \\
i_{L L}
\end{array}\right)+\left(\begin{array}{c}
1 / L_{1} \\
0 \\
0 \\
0 \\
0
\end{array}\right) u_{1}(t)
\end{aligned}
$$

Discrete incremental model has been created using Euler's implicit method given by formula (in matrix form)

$$
\boldsymbol{x}_{n+1}=[\boldsymbol{E}-\Delta \boldsymbol{A}]^{-1} \boldsymbol{x}_{n}+[\boldsymbol{E}-\Delta \boldsymbol{A}]^{-1} \Delta \boldsymbol{B}\left\{\boldsymbol{u}_{n}\right\}
$$

where 
$\boldsymbol{x}=\left(i_{L 1}, i_{L 2}, u_{C 1}, u_{C 2}, i_{L L}\right)^{T}-$ vector of state variables

$\boldsymbol{E} \quad$ is unity matrix

$\boldsymbol{A}, \boldsymbol{B}$ are matrices of system parameters

$\Delta \quad$ is integration step

$\left\{\boldsymbol{u}_{n}\right\}$ is sequence of values of input voltage

Then, discrete model suitable for numerical computing will be

$$
\begin{aligned}
& \left(\begin{array}{l}
i_{L 1} \\
i_{L 2} \\
u_{C 1} \\
u_{C 2} \\
i_{L L}
\end{array}\right)_{n+1} \\
& =\left[\boldsymbol{E}-\Delta\left(\begin{array}{ccccc}
-r_{1} / L_{1}-1 / L_{1} & -1 / L_{1} & 0 & 0 \\
0 & 0 & 0 & 1 / L_{1} & 0 \\
1 / C_{1} & 0 & 0 & 0 & 0 \\
1 / C_{2} & -1 / C_{2} & 0 & -1 / r_{2} C_{2} & -1 / C_{2} \\
0 & 0 & 0 & 1 / L_{L} & -R_{L} / L_{L}
\end{array}\right)\right] \mathrm{x} \\
& \mathrm{x}\left[\left(\begin{array}{c}
i_{L 1} \\
i_{L 2} \\
u_{C 1} \\
u_{C 2} \\
i_{L L}
\end{array}\right)_{n}+\Delta\left(\begin{array}{c}
1 / L_{1} \\
0 \\
0 \\
0 \\
0
\end{array}\right)\left\{\boldsymbol{u}_{n}\right\}\right]
\end{aligned}
$$

This model has been programed in Matlab environment.

\section{INPUT IMPEDANCE AND VOLTAGE TRANSFER CHARACTERISTICS}

Input impedance of the equivalent LCTLC circuit in the frequency domain yields [6]

$$
Z_{\text {in }}(\omega)=Z_{1}(\omega)+Z_{2}(\omega)
$$

where:

$$
\begin{gathered}
Z_{1}(\omega)=R_{11}+j \omega L_{11}+\frac{1}{j \omega C_{1}}+R_{\sigma}+j \omega L_{\sigma} ; \\
Z_{2}(\omega)=\frac{1}{Y_{2}(\omega)}
\end{gathered}
$$

and

$$
\begin{aligned}
Y_{2}(\omega)=\frac{1}{j \omega L_{m}} & +\frac{1}{R_{F e}}+\frac{1}{j \omega L_{22}}+j \omega C_{2}+ \\
& +\frac{1}{R_{22}}+1 / R_{\text {load }+j \omega L_{l o a d}}
\end{aligned}
$$

Then the normalized impedance characteristic referred to the nominal load impedance is

$$
\frac{Z_{\text {in }}(\omega)}{Z_{N}(\omega)}=\frac{Z_{1}(\omega)}{Z_{N}(\omega)}+\frac{Z_{2}(\omega)}{Z_{N}(\omega)}
$$

Normalized impedance log-characteristic depending on relative frequency is shown in Figure 2

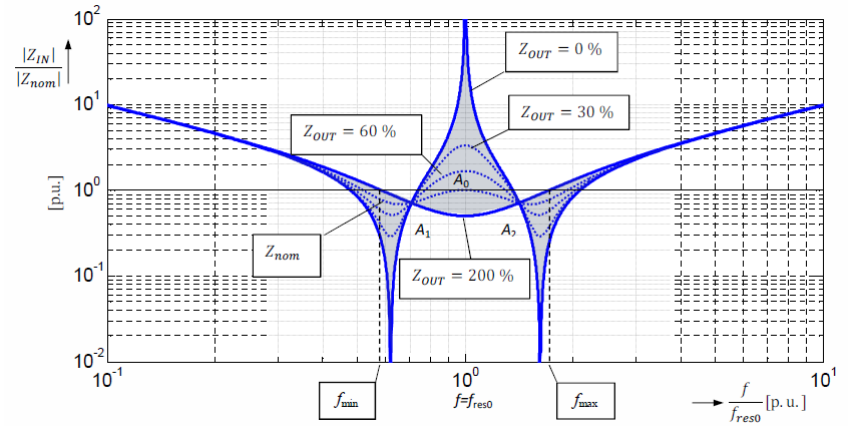

FIGURE II. INPUT IMPEDANCE TRANSFER FREQUENCY LOGCHARACTERISTICS FOR 0; 30; 60; 100 AND $200 \%$ OF THE LOAD

Similarly, the output voltage of the equivalent LCTLC circuit in the frequency domain yields

$$
\mathrm{U}_{2}(\omega)=\mathrm{U}_{1}(\omega) \times \mathrm{F}_{\mathrm{U}}(\omega)
$$

where:

$$
F_{U}(\omega)=\frac{U_{2}(\omega)}{U_{1}(\omega)}=\frac{Z_{2}(\omega)}{Z_{\text {in }}(\omega)}=\frac{Z_{2}(\omega)}{Z_{1}(\omega)+Z_{2}(\omega)}
$$

is voltage transfer or voltage gain of the LCTLC circuit. Then the normalized voltage transfer log-characteristic $F_{U}(\omega)$ depending on relative frequency is shown in Figure 3

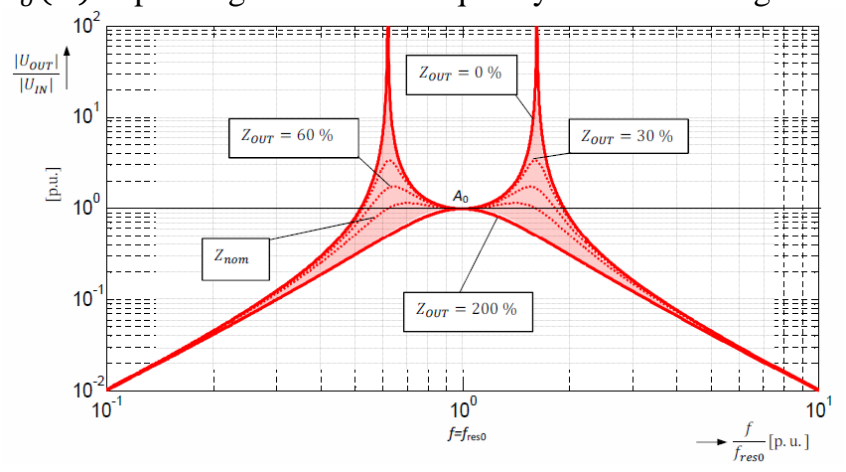

FIGURE III. OUTPUT VOLTAGE TRANSFER FREQUENCY LOGCHARACTERISTICS FOR 0; 30; 60; 100 AND $200 \%$ OF THE LOAD

Design of filter elements is given in [7], harmonic distortion can be calculated using [8].

\section{DYNAMICAL PROPERTIES OF THE SYSTEM UNDER STEP FREQUENCY CHANGE}

It is clear from the Figure 2. and 3. that impedance and voltage transfer characteristics for $200 \%$ overloading are crossing at minimal (or maximal, respectively) frequency $f_{\min }$ (or $f_{\max }$ ) whereby the input current of the circuit will be nominal one due to input impedance equal nominal impedance.

By similar way is possible to determine the optimal operation frequencies for other value of overloading and functional relation is 
$\left|f_{\text {min }}\right|_{\text {overload }}=f\left(Z_{\text {overload }}\right)$ or $\left|f_{\text {max }}\right|_{\text {overload }} f\left(Z_{\text {overload }}\right)$

to input current was be the same as nominal one.

Simulation results under step- change of inverter switching frequency during constant overload (200\%) are shown in Figure 4. for both changes: from nominal to $70 \%$ frequency, and from nominal to $140 \%$ frequency.
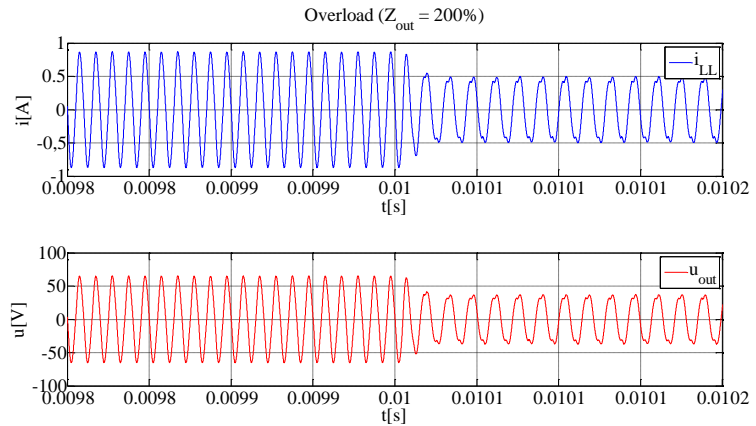

(a)

Overload $\left(Z_{\text {out }}=200 \%\right)$
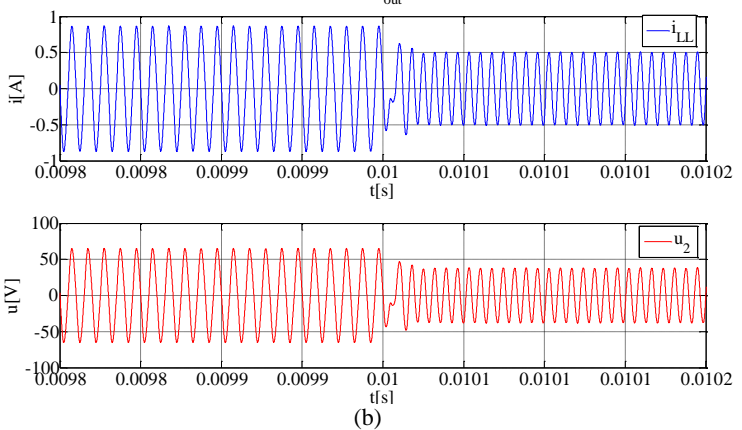

FIGURE IV. LCTLC CONVERTER RELATIVE FREQUENCY STEP CHANGE: (A) MINIMAL FREQUENCY, (B) MAXIMAL FREQUENCY

Based on input impedance frequency characteristic and voltage transfer characteristic is possible to choose minimal (or maximal, respectively) frequency fmin (or fmax) whereby the input current of the LCTLC circuit will be nominal one.

By such a way overloading operation of the LCTLC inverter can be without any overloading currents. That way, of course, can be combined with the asymmetrical control [9] of input voltage of the inverter.

By comparison of the simulation results (Figure 5.) and impedance/voltage transfer characteristic (Figure 2. Figure 3) we can confirm accuracy of the mathematical model. The output voltage during overloading and step change of the switching frequency decreases and output current reaches less than nominal value same as in the characteristics.

\section{DYNAMICAL PROPERTIES OF THE SYSTEM UNDER STEP LOAD CHANGE OF RECTIFIER OUTPUT}

The LCTLC inverter can be loaded by rectifier unlike the [10] with resistive or resistive-inductive load, Figure 4

Depending on type of rectifier switches (uni- or bidirectional ones) the rectifier can be operated in direct or regenerative modes. The mathematical model for rectified mode and dynamic states is very similar to the system equation given by (1) with the difference that initial conditions in time instant of the dynamical changes are not equal zero. The initial conditions will be given by actual values of steady state of the system.
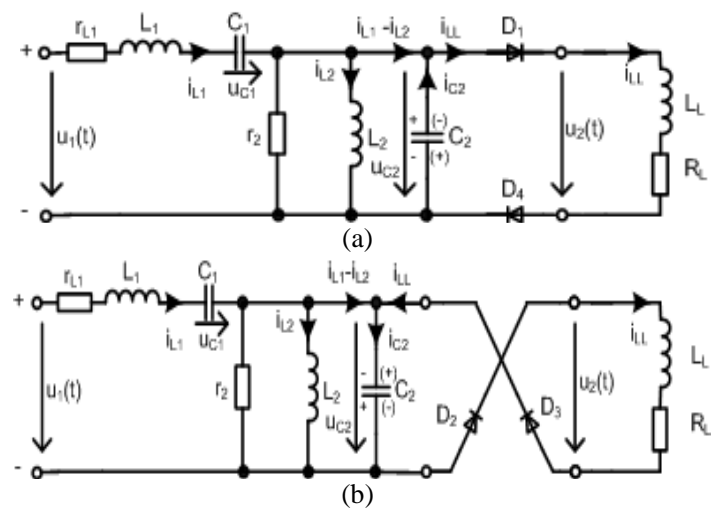

FIGURE V. EQUIVALENT CIRCUIT OF LCTLC INVERTER WITH RECTIFIER LOAD -UPPER: POSITIVE HALF PERIOD, BOTTOM: NEGATIVE HALF PERIOD

Since in positive half-period the state-space model is the same as described by (1), in the second i.e. negative halfperiod last two equations have to be changed. It is due to over-polarity of the load circuit

$$
\begin{aligned}
\frac{\mathrm{d} i_{L 1}}{\mathrm{~d} t} & =-\frac{r_{1}}{L_{1}} i_{L 1}-\frac{1}{L_{1}} u_{C 1}-\frac{1}{L_{1}} u_{C 2}+\frac{1}{L_{1}} u_{1} \\
\frac{\mathrm{d} i_{L 2}}{\mathrm{~d} t} & =\frac{1}{L_{1}} u_{C 2} \\
\frac{\mathrm{d} u_{C 1}}{\mathrm{~d} t} & =\frac{1}{C_{1}} i_{L 1} \\
\frac{\mathrm{d} u_{C 2}}{\mathrm{~d} t} & =\frac{1}{C_{2}} i_{L 1}-\frac{1}{C_{2}} i_{L 2}-\frac{1}{r_{2} C_{2}} u_{C 2}+\frac{1}{C_{2}} i_{L L} \\
\frac{\mathrm{d} i_{L L}}{\mathrm{~d} t} & =-\frac{1}{L_{L}} u_{C 2}+\frac{R_{L}}{L_{L}} i_{L L}
\end{aligned}
$$

Initial conditions in time instant of the dynamical changes are as following

$$
i_{L 1}=0 \mathrm{~V} ; i_{L 2}=0.377 \mathrm{~A} ; u_{C 1}=193 \mathrm{~V} ; u_{C 2}=0 \mathrm{~V} \text {. }
$$

Discrete dynamical state-space model is creating by the same way as in Chapter I.

Dynamical properties for switching on and switching off of the rectifier are shown in Figure 6

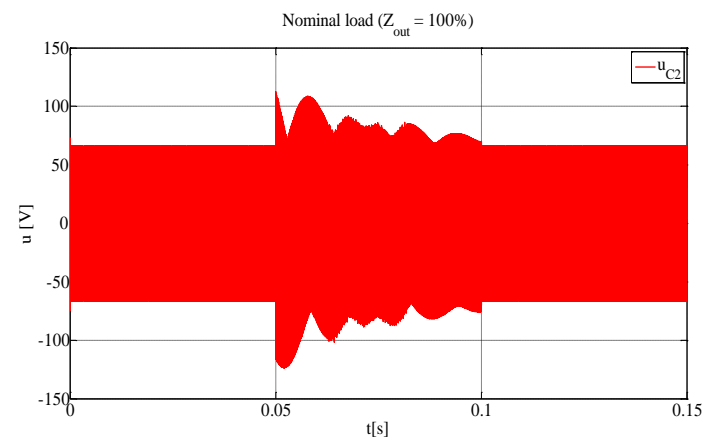

(a) 


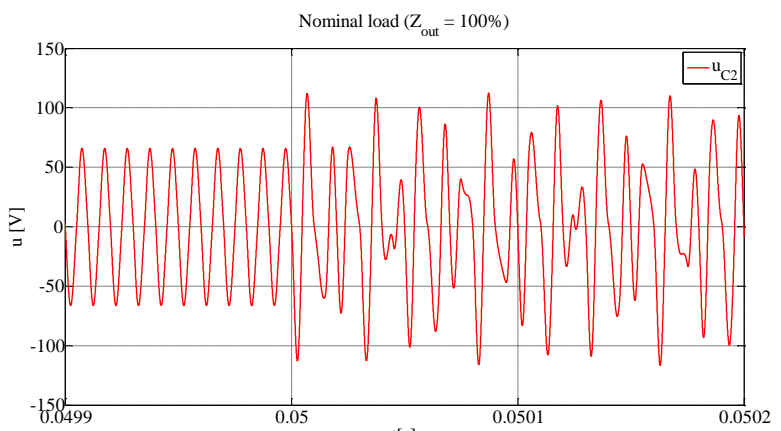

(b)

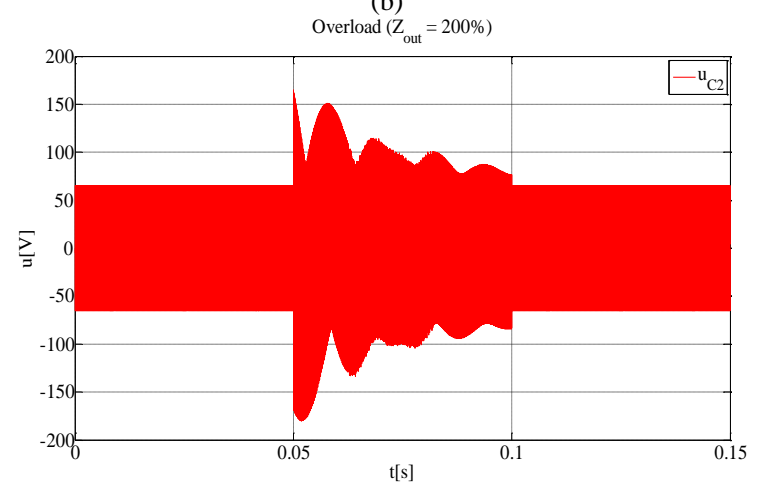

(c)

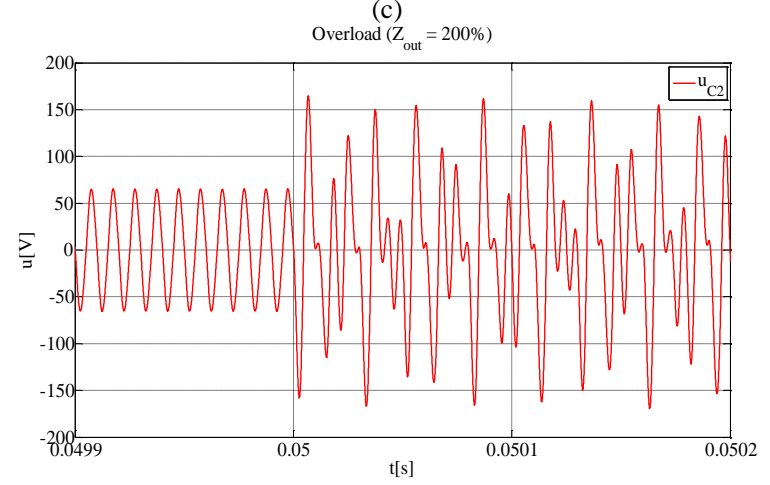

(d)

FIGURE VI. CONVERTER OUTPUT VOLTAGE DURING RECTIFIER LOAD SWITCH OFF AND SWITCH ON: (A) NOMINAL LOAD, (B) DEATIL OF OUTPUT VOLTAGE, (C) OVERLOAD, (D) DETAIL OF OUTPUT VOLTAGE

From the Figure 6. can be seen that amplitude of the voltage $u_{C 2}$ is dependent on the accumulated energy in the storage elements of the filter (the bigger energy the higher overvoltage) during rectifier load switch off.

\section{CONCLUSION}

Continuous and discrete dynamical state-space model LCLC type resonant converter was introduced with both simply resistive-inductive load and output loaded rectifier. The model was used to presenting of solution of frequency step change as well as step change of the loaded rectifier switching-off.

Using input impedance and voltage transfer characteristics was shown that during frequency step changes under even $200 \%$ overloading of the LCLC type resonant the input current will not be overcoming of nominal value.
Other dynamical state, i.e. step change of the loaded rectifier switch-off, is much more dangerous. During switching-off of the nominal rectified load the overvoltage spikes reach two-multiply of the nominal voltage, and during switching-off of the $200 \%$ rectified load the overvoltage spikes reach three-multiply of the nominal voltage value.

The simulation experiment results confirm theoretical assumptions, and presented techniques are suitable for both transient and steady-state behavior of investigated system mainly in electrical engineering, and it can be effectively combined with classical solution used non-symmetrical control technique.

\section{ACKNOWLEDGMENT}

The paper was supported from Slovak Research and Development Agency, No. APVV-0314-12.

\section{REFERENCES}

[1] M. Frivaldsky, B. Dobrucky, M. Prazenica, J. Koscelnik, "Multi-tank resonant topologies as key design factors for reliability improvement of power converter for power energy applications", In: Electrical Engineering - Archiv für Elektrotechnik, SPRINGER, 2015, ISSN 0948-7921, pp.

[2] Dobrucky, B., Marcokova, M., Pokorny, M., Sul, R: Using Orthogonal- and Discrete Transform for Single-Phase PES Transients - a New Approach, In: Proceeding of the 27th IASTED International Conference Innsbruck, Austria, February 2008, pp. 60-65, ISBN 9780-88986-711.

[3] Dobrucky, B., Benova, M., Spanik, P.: Using Complex Conjugated Magnitudes - and Orthogonal Park/Clarke Transformation Methods of DC/AC/AC Frequency Converter, In: Electronics and Electrical Engineering No.5 (93) Kaunas 2009, pp. 29 - 34, ISSN 1392 - 1215.

[4] I. Batarseh, "Steady-State Analysis of the Parallel Resonant Converter with LLCC-Type Commutation Network". Power Electronics, IEEE Transaction on, 1991, 6, (3), pp. 525-537.

[5] Y.A. Ang, M.P. Foster, C.M Bingham, D.A. Stone, H.I. Sewell and D. Howe, "Analysis of 4th-order LCLC Resonant power converters", IEE Proc. vol. 131, no. 2, pp. 169-181, 2004.

[6] B. Dobrucký, M. Frivaldský, J. Koscelník, "Choosing operational switching frequency of LCTLC resonant inverter", In: IN-TECH 2014 Int'l Conf. on Innovative Technologies, Leiria, Portugal, 10.12.09.2014, ISBN 978-953-6326-88-4, pp. 187-190.

[7] B. Dobrucky, M. Benova, M. Abdalmula, S. Kascak, "Design Analysis of LCTLC Resonant Inverter for Two-Stage 2-Phase Supply System", Automatika, 2014, 54, 3, pp. 299-307.

[8] I.V. Blagouchine, E. Moreau: Analytic method for the computation of the total harmonic distortion by the Cauchy method of residues. IEEE Transactions on Communications, Vol. 59, No. 9, Sept. 2011: pp. 2478-2491.

[9] Dobrucky, B.; Benova, M.; Kascak, S.: "Transient Analysis and Modelling of 2nd- and 4th-Order LCLC Filter Under NonSymmetrical Control". Electronics and Electrical Engineering, Technologija, Kaunas (LT), 5 (111), 2011.

[10] M. Abdamula, B. Dobrucky, "State-Space Analysis of 2nd - and 4th Order Resonant Filter LC and LCLC under Transient Condition", (2011), Journal of Applied Mathematics, Vol. IV, No. II, Slovak University of Technology in Bratislava, ISSN 1337 - 6365, pp. 333 340. 